\title{
Valproic Acid-Induced Hyperpigmentation
}

\author{
Rosa Giménez-García*, Sergio Carrasco-Molina, Belen Zambrano-Centeno \\ Department of Dermatology, Hospital Río Hortega, Valladoli, Spain
}

*Corresponding Author: Gimenez- Garcia Rosa, Department of Dermatology, Hospital Rio Hortega, Valladolid, Spain, E-mail: rosagim@hotmail.com

Received: April 04, 2017

Accepted: May 05, 2017

Published: May 20, 2017

\section{INTRODUCTION}

Valproic acid (VPA) is the most widely prescribed antiepileptic drug worldwide and it is also prescribed in the management of bipolar and schizoaffective disorders, social phobias, and neuropathic pain. Valproate is effective against all seizure types and it can be used by patients who are refractory to other anticonvulsants. It is a gold standard antiepileptic drug for children (1-3). Adverse reactions occur in about $20 \%$ of patients.

Common side effects of valproate include gastrointestinal disturbances, sialoadenitis, tremor, bodyweight gaining, encephalopathy symptoms, platelet disorders, pancreatitis, liver toxicity and teratogenicity (2-7). There are only a few cases of reports about mucocutaneous side effects due to valproic acid in the literature (816). We report a case of lip and gingival hyperpigmentation induced by VPA.

\section{CASE REPORT}

A 16 year-old male patient, with epilepsy presented to us with lip hyperpigmentation. He had personal and family history of penicillin allergy. Absence and myoclonic epilepsy were not controlled with phenobarbital and then the therapy was switched to valproate. Two weeks after VPA had been iniciated, hyper pigmentation on his lips and gingival mucous developed. He did not take concomitant medications. Physical examination showed slate-gray pigmentation without infiltration on his lips [Figure 1]. Laboratory testing included liver function test, complete blood cell count, serum urea and creatinine were normal. Lip and mucous hyperpigmentation due to valproic acid was suspected therefore management consisted of the replacement with phenytoin. One month after discontinuation of VPA clearing of lesions was noted.

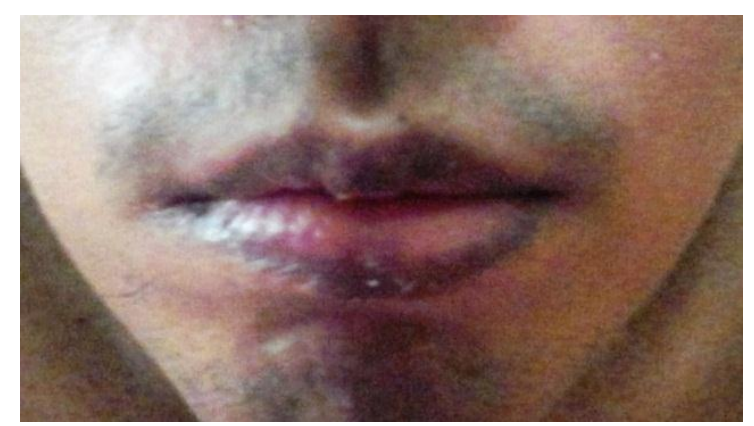

Figure 1: Physical examination showed slate-gray pigmentation without infiltration on his lips.

\section{DISCUSSION}

Drug-induced hyperpigmentation frequently occurs as post-inflammatory changes of a resolving drug-induced rash, but also directly promote through stimulation of melanin production, deposition of iron following vessels damage and/or deposition of drug (or drug metabolite) within the skin. Drugs of several classes are associated with skin or mucous membrane pigmentation and include nonsteroidal anti-inflamatory drugs, antimalarials, amiodarone, antineoplasic agents, tetracyclines, heavy metals, clofazimine, oral contraceptives, psycotropic drugs, anticonvulsants such as hydantoin, phenytoin and barbiturates (18-24). Other drugs reported to induce skin hyperpigmentation are amiodarone and some antihypertensives such as diltiazem, telmisartan and amlodipine (25-29).

As an antiepileptic, valproic acid has been shown effective in adults and children with generalized seizures (absence, tonic-clonic seizures and myoclonic epilepsy), partial seizures (simple, complex, secondary generalised) and combination seizures. As for 
the mechanism of action of valproate, it involves a variety of mechanisms, including increased gamma-amino butyric acid (GABA)ergic transmission, reduced release and/or effects of excitatory amino acids, blockade of voltage-gated sodium channels and modulation of dopaminergic and serotoninergic transmission (3).

With regard to the published cutaneous secondary effects produced by valproate, there are several articles referred to valproate side effects (8-16).Cutaneous vasculitis is a reported side effect that was described in patients treated with valproate (12-13). Change in hair colour and curly hair are rare side effect produced by valproate $(9,10)$. Other reported side effects are a yellow nail pigmentation or onycholysis (15, 17).

Hyperpigmentation of the lips can be caused by many reasons, including physiologic changes, genodermatoses, inflammatory disease, endocrinologic disorders, drugs and chemicals, benign and malignant neoplasm and other nonmelanotic conditions. Drugs may cause a post inflammatory hyperpigmentation that is a typical non-specific reaction of fixed drug reactions. Hyperpigmentation of the lips is a common presentation in clinical practice that require a systematic approach for the diagnostic that includes a complete medical history, family history, history of cosmetic and medication use, and evaluation of systemic symptoms (30). The list of medications that can cause lip or oral hyperpigmentation include sulphonamides, nonsteroidal anti-inflammatory drugs, carbamacepine, phenothiazines, minocycline, zidovudine, cyclophosphamide, doxorubicin, escitalopram, levodopa, nicotine, tacrolimus, cotrimazole, colchicines, ketoconazole, pyrimethamine and barbiturates $(30,31)$. Bluegray mucocutaneous discoloration associated with Ezogabine-a new anticonvulsant- has been reported (32). To our knowledge this is the first reported case of lip and gingival hyper pigmentation due to valproic acid.

\section{REFERENCES}

[1] Lewis JR. Valproic acid (Depakene): a new anticonvulsant agent. JAMA 1978, 240:21902192.

[2] Perucca E. Pharmacological and therapeutic properties of valproate: a summary after 35 years of clinical experience. CNS Drugs 2002, 16: 695-714.

[3] Guerrini R. Valproate as a mainstay of therapy for pediatric epilepsy. Paediatr Drugs 2006, 8: 113-129.
[4] Mnif L, Sellami R, Masmoudi J. Valproic Acid and Hepatic Steatosis: A Possible Link? About a Case Report. Psycho pharmacol Bull. 2016; 46:59-62.

[5] Jomli R, Nacef F, Douki S. Acute pancreatitis induced by valproic acid. Encephale. 2013; 39:292-5.

[6] Derin H, Derin S, Oltulu P, Özbek O, Çaksen H. Pediatric Sialadenosis Due to Valproic Acid. J Craniofac Surg. 2017 Mar;28(2):e127-e129.

[7] Mauz PS, Mörike K, Kaiserling E, Brosch S. Valproic acid-associated sialadenosis of the parotid and submandibular glands: diagnostic and therapeutic aspects. Acta Otolaryngol. 2005; 125:386-91.

[8] Gillman MA, Sandyk R. Nicotinic acid deficiency induced by sodium valproate. S Afr Med J. 1984 23; 65:986.

[9] Jeavons PM, Clark JE, Harding GF. Valproate and curly hairl. Lancet. 1977; 12; 1(8007):359.

[10] Gerstner T, Lipinski C, Longin E, König S. Valproate-induced change in hair color. J Am Acad Dermatol. 2008; 58(2 Suppl): S63-4.

[11] Cohen O, Sharma S. Sterile matrix grafting for onycholysis in the setting of valproic acid use. JAAD Case Rep. 2015 2; 1:356-8.

[12] Kamper AM, Valentijn RM, Strickler BH, Purcell PM. Cutaneous vasculitis induced by sodium valproate. Lancet. 1991 23; 337(8739):497-8.

[13] Lasić D, Ivanišević R, Uglešić B, Cvitanović MZ, Glučina D, Hlevnjak I. Valproate-acidinduced cutaneous leuko cytoclastic vasculitis. Psychiatr Danub. 2012; 24: 215-8.

[14] Solak B, Kara RO, Erdem T. Various simultaneous nail changes due to valproic acid use Journal Cutaneous and Ocular Toxicology 2011;36:96-97.

[15] Jenerowicz D, Szulczynska-Gabor J, Polanska A, et al. Finger-nail onycholysis, leukonychia and acrocyanosis in a patient treated with valproic acid-case report. Postepy Dermatol Alergol 2011; 28: 522-524.

[16] Buka R, Hille R, McCormack P. Yellow nail pigmentation following Depakote therapy. J Drugs Dermatol. 2003; 2:545-7.

[17] Cohen O, Sharma S. Sterile matrix grafting for onycholysis in the setting of valproic acid use. JAAD Case Rep. 2015; 1:356-8.

[18] Dereure O. Drug-induced skin pigmentation. Epidemiology, diagnosis and treatment. Am J Clin Dermatol. 2001; 2:253-62.

[19] Crowson AN, Magro CM. Recent advances in the pathology of cutaneous drug eruptions. Dermatol Clin. 1999; 17:537-60

[20] Lerner EA, Sober AJ. Chemical and pharmacologic agents that cause hyperpigmentation or hypopigmentation of the skin. Dermatol Clin. 1988; 6:327-37. 
[21] Vázquez-Bayo C, Rodríguez-Bujaldón AL, Jiménez-Puya R, Galán-Gutiérrez M, MorenoGiménez JC. Capecitabine-induced hyperpigmentation. Actas Dermosifiliogr. 2007; 98:491-493;

[22] Li CC, Malik SM, Blaeser BF, Dehni WJ, Kabani SP, Boyle N, Toner M, Woo SB. Mucosal pigmentation caused by imatinib: report of three cases. Head Neck Pathol. 2012; 6:290-295;

[23] Kauzman A, Pavone M, Blanas N, Bradley G. Pigmented lesions of the oral cavity: review, differential diagnosis, and case presentations. J Can Dent Assoc. 2004; 70:682-683.

[24] Meleti M, Vescovi P, Mooi WJ, Van der Waal I. Pigmented lesions of the oral mucosa and perioral tissues: a flow-chart for the diagnosis and some recommendations for the management. Oral Surg Oral Med Oral Pathol Oral Radiol Endod. 2008; 105:606-616.

[25] Jaworski K, Walecka I, Rudnicka L, Gnatowski M, Kosior DA. Cutaneous adverse reactions of amiodarone. Med Sci Monit. 2014; 20:23692372.

[26] Molly Boyer, Rajani Katta MD, and Ramsey Markus MD. Diltiazem-induced photo distributed hyperpigmentation. Dermatol Online J. 2003; 9:10.

[27] Kubo Y, Fukumoto D, Ishigami T, Hida Y, Arase S. Diltiazem-associated photo distributed hyperpigmentation: report of two Japanese cases and published work review. J Dermatol. 2010 Sep; 37:807-811.

[28] Giménez-García R. Hyperpigmentation induced by combination therapy with telmisartanhydrochlorothiazide. J Clin Hypertens (Greenwich). 2016; 18:361-362.

[29] Erbagci Z. Amlodipine associated hyperpigmentation. Saudi Med J. 2004; 25: 103-105.

[30] Vachiramon V, McMichael AJ. Approaches to the evaluation of lip hyperpigmentation. Int $\mathrm{J}$ Dermatol. 2012; 51: 761-770.

[31] Gondak R.O. Oral pigmented lesions: clinicopathologic and review of the literature. Med Oral Patol Oral Cir Bucal. 2012; 17: 919924.

[32] Garin Shkolnik T, Feuerman H, Didkovsky E, Kaplan I, Bergman R, Pavlovsky L, Hodak E. Blue-gray mucocutaneous discoloration: a new adverse effect of ezogabine. JAMA Dermatol. 2014;150:984-989.

Citation: Gimenez- Garcia Rosa, Sergio Carrasco-Molina, Belen Zambrano-Centeno. Valproic Acid Induced Hyperpigmentation. 2017; 2(1):16-18. doi: dx.doi.org/10.20431/2456-0022.0201003.

Copyright: (C) 2017 Authors. This is an open-access article distributed under the terms of the Creative Commons Attribution License, which permits unrestricted use, distribution, and reproduction in any medium, provided the original author and source are credited. 